\title{
Correction to: ACE2 activation protects against cognitive decline and reducesamyloid pathology in the Tg2576 mouse model of Alzheimer's disease
}

\author{
Charles E. Evans ${ }^{1,2}$. James S. Miners ${ }^{3}$ (D) Giulia Piva $^{2}$. Christine L. Willis ${ }^{4}$ (D) David M. Heard ${ }^{4}$. Emma J. Kidd ${ }^{2}$ (D) \\ Mark A. Good ${ }^{1}$ (D) Patrick G. Kehoe ${ }^{3}$ (D)
}

Published online: 27 September 2020

(c) Springer-Verlag GmbH Germany, part of Springer Nature 2020

\section{Correction to: Acta Neuropathologica (2020) 139:485-502 https://doi.org/10.1007/s00401-019-02098-6}

Unfortunately, the acknowledgement section was not included in the original publication. The complete acknowledgement section is given here.

\section{Acknowledgements}

This research was conducted thanks to an Alzheimer's Disease Research (ADR) project grant from the Bright Focus Foundation (A2016582S), Kehoe was supported by a Fellowship from the Sigmund Gestetner Foundation and Miners by an Alzheimer's Research UK Senior Research Fellowship.
Publisher's Note Springer Nature remains neutral with regard to jurisdictional claims in published maps and institutional affiliations.

The original article can be found online at https://doi.org/10.1007/ s00401-019-02098-6.

James S. Miners

scott.miners@bristol.ac.uk

$\triangle$ Patrick G. Kehoe

Patrick.Kehoe@bristol.ac.uk

1 School of Psychology, Cardiff University, Cardiff CF10 3AT,

UK

2 School of Pharmacy and Pharmaceutical Sciences, Cardiff University, Cardiff CF10 3NB, UK

3 Dementia Research Group, Translational Health Sciences, Bristol Medical School, University of Bristol, Level 1 Learning and Research, Southmead Hospital, Bristol BS10 5NB, UK

4 School of Chemistry, University of Bristol, Cantock's Close, Bristol BS8 1TS, UK 